\title{
"TRADUZIR É O MODO VERDADEIRO DE LER UM TEXTO": CALVINO E A TRADUÇÃO, A TRADUÇÃO DE CALVINO
}

\author{
Roberta Barni* \\ Universidade de São Paulo
}

\begin{abstract}
Resumo: O artigo tem por objetivo apresentar e tecer considerações sobre a relação de Italo Calvino com a tradução a partir de alguns textos do autor que lidam especificamente com esse tema, além de comentar um de seus personagens romanescos. As contribuições de Calvino nesse campo são inúmeras e consistem em reflexões e observações, bem como em sua experiência tradutória.
\end{abstract}

Palavras-chave: Calvino. Tradução. Literatura italiana. Língua italiana.

\footnotetext{
* Roberta Barni é graduada em Direção Teatral pela Escola de Comunicações e Artes (ECA) da Universidade de São Paulo (1981), obteve a especialização em Tradução-Italiano (Pós-Graduação Lato Sensu) pela Faculdade de Filosofia, Letras e Ciências Humanas (FFLCH) da USP (1995) pela qual também obteve o mestrado em Letras (Língua e Literatura Italiana) (1999) e doutorado em Lingüística (Semiótica e Lingüística Geral Tradutologia) (2005). Foi bolsista de pós-doutorado no exterior da CAPES, realizando seu trabalho de pesquisa em teoria literária e italianistica na Universidade de Bologna (2007-2008). Atualmente é professora doutora de Literatura Italiana junto ao Departamento de Letras Modernas (DLM) da FFLCH da USP. São Paulo, Brasil. E-mail: rbarni@usp.br
} 


\title{
"TRANSLATING IS THE TRUE WAY TO READ A TEXT": CALVINO AND TRANSLATION, CALVINO'S TRANSLATION.
}

\begin{abstract}
The purpose of this article is to present and discuss Italo Calvino's relationship with translation, starting from some texts that deal specifically with this subject and also taking in consideration one of his characters. Calvino's contributions in this field are numerous and consist of reflections and observations, as well as of his own translations experiences.
\end{abstract}

Keywords: Calvino. Translation. Italian literature. Italian language.

Tudo pode mudar, mas não a língua que carregamos dentro de nós e que, aliás, nos contém dentro de si como um mundo mais exclusivo e definitivo que o ventre materno. Italo Calvino

Como o título sugere, o objeto desse texto é considerar a relação de Italo Calvino com a tradução a partir de alguns textos do autor, publicados, que remetem explicitamente à tradução. As contribuições de Calvino nesse sentido são inúmeras: reflexões, observações, experiências. Para tanto, tornam-se necessárias algumas observações preliminares.

A primeira delas é que Calvino apresenta a peculiaridade de ter nascido, por assim dizer, sob o signo da multiculturalidade - ou do cosmopolitismo, como diria o crítico italiano Asor Rosa (2001) - e do multilinguismo. Basta pensar em seu nascimento em Santiago de Las Vegas, em Cuba. Embora ele tenha voltado ainda muito pequeno à Itália, trata-se de um fato ao qual o autor não era indiferente e que, aliás, despertava sua curiosidade. Tanto assim que, ao se tornar partigiano, escolheu como nome de guerra Santiago, justamente. Sabemos também que, após sua participação na resistência durante a Segunda Guerra, Calvino se matricula na Faculdade de Letras de Turim, e concluirá seu curso com uma 
tese sobre Joseph Conrad, isto é, um escritor britânico de origem polonesa - e aqui temos um período de "convivência", por assim dizer, com a literatura inglesa, e o primeiro contato com a tradução propriamente dita. Há também outros fatores pessoais a considerar: Italo Calvino, como se sabe, casa-se com uma argentina, e vai precisamente a Cuba para celebrar seu casamento com Chichita que, como o autor nos revela, fala com ele no espanhol de Rio de La Plata. O casal vai viver em Paris. A filha, Giovanna Abigail, fala com o pai "nel francese delle scolaresche popolari parigine" 1 . Uma verdadeira babel doméstica, que, de certo modo, recorda a da família de origem. Pai da Ligúria, mãe da Sardenha - mãe severa, que, ao tomar as rédeas da educação de Calvino, banirá a expressão dialetal. A figura do pai, aquele pai granítico descrito com tanto sofrimento e de forma tão expressiva em $O$ caminho de San Giovanni (1995), pai frequentador de beudi e caminhos de mulas, aquele pai que sobe ao campo enquanto Calvino desce para a cidade... Pois bem, aquele pai do qual Calvino se afasta tomando a direção exatamente oposta, aquele pai conhecia um dialeto rico e expressivo, ainda sugestivo, o "dialeto antigo", dirá Calvino, ainda não desgastado ou degradado, que por certo tempo inspirará a expressão calviniana (e do qual, mais tarde, ele vai se afastar). Ainda nesse sentido, não podemos desconsiderar que, por exemplo, durante todo o intervalo parisiense - como se sabe ele morará em Paris de 1964 a 1980 - Calvino sentirá novamente a necessidade de tradução - em todos os sentidos. Tampouco podemos ignorar a breve, mas intensa, passagem pelos Estados Unidos, mais tarde exposta em Um eremita em Paris (1994), que o levará a afirmar ser Nova York sua cidade ideal.

Enfim, essa breve premissa biográfica nos auxilia na consideração atenta do caráter multicultural em que Calvino nasce e cresce e que frequentará a vida toda. É bem aqui, na minha opinião, que reside a origem daquilo que o prof. Wander de Melo Miranda denominou "espaço ao estrangeiro" (informação verbal) ${ }^{2}$, sempre presente no autor. Ou seja, a visão ampla de Calvino, uma visão que guarda um caráter 'estrangeiro' mesmo na pátria, que propor- 
ciona a liberdade do olhar da cultura estrangeira sobre a cultura local. Esse é, na prática, o espaço de sua "natural”, "inata” consciência do outro, da alteridade, do estrangeiro, que nasce, podemos dizer, pari passu com nosso autor (e, numa segunda etapa, se reafirmará pari passu com sua vida intelectual, principalmente a do colaborador da editora Einaudi). Poderíamos ir mais longe e afirmar que Calvino nasce em clima de bilinguismo. Embora seu percurso intelectual seja variado também quanto à avaliação que faz e ao peso que confere ao dialeto em sua expressividade, o autor afirma claramente ter vivido em ambiente dialetal até aproximadamente seus vinte e cinco anos (CALVINO, 2002b, p. 227):

\begin{abstract}
Ho vissuto quasi ininterrottamente a Sanremo i primi venticinque anni della mia vita, in tempi in cui la popolazione autoctona era ancora la maggioranza. Vivevo in un ambiente agricolo dove si parlava prevalentemente il dialetto, $e$ mio padre [...] parlava un dialetto molto più ricco e preciso ed espressivo di quello dei miei coetanei. Sono dunque cresciuto imbevuto di dialetto, ma senza mai imparare a parlarlo [...], (Devo dire che non ho mai appreso a parlare fluentemente in nessun idioma, anche perché per carattere sono sempre stato di poche parole; e presto i miei bisogni espressivi e comunicativi si sono polarizzati sulla lingua

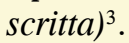

O que Calvino faz inicialmente, e o diz claramente, é utilizar o dialeto, aquele dialeto, como modelo, para sua língua de escritor, porque, sentindo como falsa a língua utilizada pela maioria das pessoas que escrevem, a proximidade com o falado popular lhe parecia uma garantia de autenticidade. Lembramos aqui a centralidade da reflexão daqueles anos em torno de uma língua italiana, presente constantemente na vida do escritor. Em 1959, ao responder a uma das 9 perguntas sobre o romance ele diz se valer do dialeto como ponto de referência em determinadas escolhas linguísticas e lexicais: "Una volta stabilito che sotto al mio italiano c è il dialetto $x$, 
sceglierò di preferenza vocaboli, costruzioni, usi, che si rifanno al clima linguistico $x$, anziché vocaboli e costruzioni e usi che si rifanno ad altre tradizioni" (CALVINO, 2002a, p. 34) ${ }^{4}$. E acrescenta que é possível prosseguir com esse método para dar coerência e clareza a uma linguagem narrativa, contanto que ele não atue como limitação das capacidades expressivas. Caso isso aconteça, "non c'è che mandarlo al diavolo" 5 .

Como já foi observado, a influência dialetal em Calvino se mostra mais forte nos textos iniciais, até o "Barone rampante" (1957). $\mathrm{Na}$ realidade, o próprio autor tem um percurso mutável no que tange ao uso do dialeto, desde um momento inicial em que deseja utilizá-lo até encontrar, mais tarde, uma cifra estilística e expressiva própria. Em Il midollo del leone (1980), Calvino se pronuncia contrário ao uso do dialeto: "la lingua letteraria deve continuamente tenersi attenta ai volgari parlati, e nutrirsene e rinnovarsene, ma non deve annullarsi in essi, né scimmiottarli per gioco"6. As afirmações contrárias ao uso do dialeto e a favor de sua dissolução em outra expressão, “como plasma oculto mas vital”, são claramente anteriores ao prefácio de 1964 a Il sentiero dei nidi di ragno ${ }^{7}$, e não se limitam ao famoso parágrafo de Il midollo del leone. Segundo Bertone (1994, p. 77), Pavese teria sido o prosador que mais levou Calvino ao caminho da absorção do dialeto e, em paralelo, a uma superação do empasse regional. Enfim, ao menos por certo período, temos um Calvino que se traduz e que quer traduzir ao ler o mundo. Que precisa 'inventar' uma língua inexistente a cada vez que se debruça numa nova obra. Mas essa língua se alimenta, como diz o próprio autor, do dialeto. E o prazer do dialeto ainda pode ser notado em alguns de seus escritos, embora Calvino afirme o contrário. O conto "Dall'opaco" (1971) por exemplo, hoje contido em La Strada di San Giovanni ${ }^{8}$, centra-se totalmente em um jogo lexical e imagético do autor sobre um vocábulo dialetal, uma tentativa de traduzir em palavras uma imagem cada vez mais precisa aquela dos campos da Ligúria, dos típicos "terraços" em degraus —, de traduzi-la em uma linguagem descritiva que se apresenta num crescendo de síntese e de eliminação do supérfluo. A palavra é 
tão importante que o escritor sente que só poderia usar o seu dialeto para descrever aquela paisagem tão específica. A palavra dialetal, conforme afirma Bertone ${ }^{9}$, e precisamente a partir desse exemplo, vai se tornando metalinguística, até se tornar símbolo. Nem cabe aqui considerar o peso da questão política subjacente a essa escolha por uma língua a ser inventada e fora da hegemonia do toscano em Calvino; será suficiente recordar essa presença. O que mais nos interessa é que, aqui, tocamos outro aspecto fundamental. Foi dito em diversas ocasiões que Calvino é um autor visual, que sua escrita muitas vezes nada mais é do que uma "tradução intersemiótica" daquilo que seu olhar curioso e inquieto apreende. Esse aspecto em si é tão relevante que poderia ser objeto de outro estudo específico. Aqui, no entanto, podemos observar como a tradução do mundo é, em primeiro lugar, parte de si, para depois, então, se alargar às coisas do mundo. Lê-se em Palomar:
Il signor Palomar pensa che ogni traduzione richiede un'altra traduzione e così via. Si domanda: "Cosa voleva dire morte, vita, continuità, passaggio, per gli antichi Tolte- chi? E cosa può voler dire per questi ragazzi? E per me? Eppure sa che non potrebbe mai soffocare in sé il bisogno di tradurre, di passare da un linguaggio all'altro, da figure concrete a parole astratte, da simboli astratti a esperienze concrete, di tessere e ritessere una rete d'analogie. Non interpretare è impossibile, come è impossibile trattenersi dal pensare. (CALVINO, 1983, p. 100) ${ }^{10}$.

Essas coisas do mundo, à medida que o tempo passa, Calvino parece observá-las e descrevê-las cada vez mais de um ponto de vista fenomenológico, retornando às próprias coisas com um olhar puro, novo, o mais inocente possível. Nesse sentido, Palomar e seus experimentos descritivos parecem constituir seu exercício máximo. Calvino afirma, em seu ensaio Mondo scritto e mondo non scritto, que dá o nome ao volume: "Forse la prima operazione per rinnovare un rapporto tra linguaggio e mondo è la più semplice: 
fissare l'attenzione su un oggetto qualsiasi, il più banale e familiare, e descriverlo minuziosamente come se fosse la cosa più nuova e interessante dell'universo" (CALVINO, 2002a, p.122) ${ }^{11}$. Não seria essa a declaração de uma verdadeira redução fenomenológica, o exercício da filosofia fenomenológica em ficção?

$\mathrm{O}$ segundo aspecto fundamental é a experiência de trabalho, a vivência de Calvino com relação à tradução. Dessa vez estamos diante de um aspecto não duplo, mas múltiplo. Se até agora notamos as relações pessoais que aproximam Calvino da tradução em sentido lato, agora podemos observar que ele experimenta a tradução editorial em três planos diferentes, de três pontos de vista diversos:

1. como editor;

2. como autor traduzido;

3. como tradutor (ainda que rara e escassa, sua experiência de tradutor nada teve de superficial).

Em sua vida pessoal, a tradução vai ganhando cada vez mais espaço. Depois de se casar com uma intérprete, ele se muda para a França e, se em 1963, dirá nunca ter tentado traduzir ${ }^{12}$, em 1965 começa a traduzir Les fleurs bleu (1965) de Raymond Queneau, uma operação temerária, arriscada que, no entanto, parece iluminar uma faceta inusitada do Calvino "leitor dos outros".

No que tange ao Calvino editor, sua contribuição talvez mais marcante e evidente à tradução é aquela contida na carta intitulada "Sul tradurre" (1963) endereçada originalmente ao diretor da revista Paragone e mais tarde publicada em livro ${ }^{13}$. Nessa carta, Calvino toma a defesa da tradutora Adriana Motti e, ao mesmo tempo, procura sugerir e delimitar o papel que, na sua opinião, um crítico digno de tal nome deveria ter. A carta responde a uma crítica (que Calvino considera injusta e demasiado dura) de Claudio Gorlier à tradução italiana de A Passage to India (1924) de E.M. Forster, publicada, naturalmente, pela Einaudi, editada sob sua batuta. Trata-se de uma carta embebida de ironia, nem sempre sutil, mas também, e sobretudo, de reflexões absoluta e espantosamente atuais. 
Calvino constrói um discurso no qual estabelece um diálogo com cada observação do crítico, respondendo ponto por ponto à sua matéria. É preciso frisar, que o crítico, na verdade, fora bastante corrosivo, e Calvino não resiste à tentação de ironizar sua atitude, sempre que possível, ao longo dessa sua réplica. Tentarei resumir os argumentos de Calvino de maneira sistemática e descritiva:

- Uma boa crítica, que entre no mérito da tradução, é necessária, quer para a editora, quer para o tradutor e para o público;

- Ao crítico, cabe uma responsabilidade técnica absoluta, de outro modo o trabalho se torna contraproducente e nada mais faz que desmoralizar o tradutor;

- A crítica, portanto, deve ser realizada seriamente, com amostragens válidas, e não se basear numa expressão que "non gli garba [al critico]" está referenciado na nota 13, acima. Em todo caso é Calvino, 2002a, p. 48 ) [não agrada ao crítico], o qual, em dois minutos, destrói talvez um trabalho enorme, talvez bom, e com consequências ruins para o tradutor, sujeito a uma única critica, e não a diversas, como no caso, por exemplo, do escritor.

Já nesses argumentos, notamos como, infelizmente, o panorama atual parece repetir uma situação lamentável que já existia na Itália daqueles tempos. Carecemos de (boas) críticas à tradução, aliás, nos últimos anos carecemos de qualquer crítica. Tanto no Brasil como (ainda) na Itália. Mas não nos aventuraremos nesse tema, que constitui, em si, um estudo à parte. Aqui basta enfatizar a atualidade das reflexões do nosso autor sobre a pertinência, a necessidade até, de uma crítica às traduções literárias, para todos os sujeitos envolvidos nessa relação: do editor ao tradutor ao leitor, justamente. Em seguida, Calvino discorre sobre a disponibilidade real de bons tradutores, afirmando que, apesar de ter aumentado o número de jovens de boa vontade que "conhecem bem ou discretamente uma língua estrangeira”, esse aumento não corresponde 
a uma "base maior" de tradutores entre os quais poder escolher. Isso porque se é verdade que o número de jovens que conhecem uma língua estrangeira aumentou, também é verdade que o número daqueles jovens capazes de escrever italiano com dotes de agilidade, de segurança na escolha lexical, de economia sintática, de sentido dos diversos níveis linguísticos (ou seja, com inteligência de estilo), é cada vez menor. Mas o que Calvino entende por "inteligência do estilo"? Numa de suas habituais digressões, ele abre aqui uma brecha reveladora: "inteligência de estilo consiste, por um lado, em compreender as peculiaridades estilísticas do autor a traduzir, e, por outro, em saber propor os equivalentes em italiano, numa prosa que se leia como se tivesse sido pensada e escrita diretamente em italiano): os dotes, precisamente, nos quais reside o talento singular do tradutor". Calvino afirma também que, além desses dotes técnicos, o tradutor precisa ter dotes morais, que consistem na insistência e na persistência do tradutor, impelido por um tormento de perfeição que, declara, "tem que se tornar uma espécie de loucura metódica". Calvino, portanto, sugere aqui que seu ideal tradutório é uma tensão (e atenção) constante à literariedade, alimentada por uma espécie de obsessão, capaz de levar a um texto de chegada vestido de trajes locais, sem rasgos capazes de revelar-lhe a origem. Noutras palavras, ao enfrentar a antiga questão, Calvino se mostra aqui mais propenso, utilizando a terminologia moderna, à tendência domesticadora.

O segundo texto calviniano mais conhecido sobre tradução, cujo título já é bastante eloquente, é "Tradurre è il vero modo di leggere un testo" [Traduzir é o modo verdadeiro de ler um texto] de 1982. Escrito originalmente para uma comunicação apresentada em Roma, inaugurando, precisamente, um congresso de tradutores, está hoje publicado em Mondo scritto e mondo non scritto (2002a, p. 84-91). Nesse texto, Calvino enfatiza a importância do ato comunicativo da escrita, já que, para que um livro possa ser traduzido, deve haver motivos tanto de originalidade quanto de universalidade, e nesse sentido o autor considera ter a linguagem uma importância máxima, porque - e nessa altura Calvino fala de 
"voz do texto", literalmente voz - "para obter a atenção do leitor esta voz deve ter "certo tom, certo timbre, certa vivacidade" sendo portanto falaciosa a ideia - superficial - de que um escritor de tom neutro seria o mais "exportável", além de apresentar menos problemas de tradução. Partindo da ideia de literatura como comunicação, esta deve ser estabelecida mediante o "sotaque peculiar do escritor", e isso pode se dar mesmo em nível coloquial. O autor conclui afirmando ser a tradução uma arte (e aqui poderíamos abrir um parêntesis sobre o vocábulo, em todo o significado que essa palavra carrega em si, mesmo apenas potencialmente), e diz "il passaggio di un testo letterario [...] in un'altra lingua richiede ogni volta un qualche tipo di miracolo" (CALVINO, 2002a, p.86, 4-91, grifo meu) ${ }^{14}$. Então o tradutor é aquele que coloca em jogo a si mesmo por inteiro, para traduzir o que é intraduzível. Milagre, sabemos, é um fato extraordinário, que beira o inacreditável. Algo, em sua essência, impossível. É altamente sugestiva essa configuração da tradução como milagre.

Com sua precisão e nitidez de diamante, como dizia Elsa Morante Calvino afirma que muitas vezes se decepciona com as traduções de seus livros, porque considera que se muitas vezes se perdem as sutilezas expressivas do texto, mesmo em traduções muito "fiéis" (ou por isso mesmo? Como não pensar nessa antiga questão nos termos ciceronianos, ou, ainda, nos termos de Horácio, em sua Arte poética? (entre 19 e 13 a.c.). Calvino apresenta, a título de exemplo, a decepção causada por uma tradução em que se perde ironia ou ritmo, como no caso de uma oração subordinada, que o autor sente veloz em seu texto, mas que na tradução adquire "importância e peso injustificados". Para a seguir reafirmar: "Tradurre è il vero modo di leggere un testo" e, "per lo scrittore, riflettere sulla traduzione di un proprio testo, il discutere con il traduttore, è il vero modo di leggere se stessi, di capire bene cosa ha scritto, e perché" (CALVINO, 2002a, p. 87) ${ }^{15}$. Nessa passagem, o autor toca outro ponto nevrálgico para a tradução, em geral capaz de gerar riqueza, mas nem sempre realizável, que é o da colaboração entre o autor e o tradutor. Que, para além do interesse comum e 
imediato de obter-se uma boa tradução, passa a significar, para Calvino, um momento de reflexão que lhe revela, banhado por nova luz, tanto o próprio texto, quanto as motivações que o levaram a escrever aquele texto, e daquela maneira. Fala, ainda, em "spirito del testo", afirmando que quanto menos o tradutor se sentir tentado a fazer de sua tradução uma cópia literal, tanto mais estará apto a salvar esse espírito. Ademais, considera extremamente importantes as perguntas que um tradutor dirige a um autor, arriscando-se a dizer que, conforme as perguntas, ele, Calvino, consegue emitir um juízo sobre a qualidade do tradutor. Afirma crer na função de uma editora, na colaboração entre editor e tradutor, e se queixa (já naquela época) de que essa colaboração estava ficando rara, quase inexistente. A seguir, então, o escritor toca numa questão central em toda a sua reflexão, quase uma obsessão: as dificuldades específicas de um escritor italiano - e, portanto, dos tradutores -, que, a cada vez, têm um problema com a própria língua, pela distância existente entre a fala natural e a linguagem escrita: os italianos nunca terminam uma frase, o italiano corrente tende a "desaparecer o tempo todo no nada", ao passo que o escrito pede que se termine a fase, abrindo aí uma bela distância entre os dois. Para ele, "lo scrittore italiano vive sempre in uno stato di nevrosi linguística" ${ }^{16}$ (CALVINO, 2002a, p. 90), até porque precisa se distanciar das linguagens setoriais, mas não pode usar a linguagem falada comum, já que trabalha dentro de uma tradição literária que tem por cerne a poesia, e não a prosa, com as consequências que se pode depreender dessa falta de um modelo válido. Em suma, a problematização da linguagem, somada às particularidades complicadoras do italiano, criam em Calvino uma tensão constante em relação à própria expressão. Diante de tudo isso, Calvino conclui, com sua marca um tanto melancólica, um tanto irônica: "lo scrittore italiano può insegnare una sola cosa: affrontare la depressione, male del nostro tempo, difendendosi con l'ironia" (CALVINO, 2002a, p. 91) ${ }^{17}$.

Haveria, ainda, que comentar sua empreitada tradutória mais conhecida, ou seja, a tradução para o italiano de Les fleurs bleues 
de Queneau. Nela, Calvino decide experimentar na prática a teoria que elabora a partir da leitura de Mounin (1965) e da linguística de Saussure. O posfácio calviniano (1984) apresenta inúmeros exemplos das diversas dificuldades tradutórias do texto de Queneau, descrevendo assim o caminho intencional do tradutor. Mas aqui nos interessa apontar, antes, o que Calvino diz a esse propósito em seu "Furti ad arte. Conversazione con Tullio Pericoli" (1980), hoje contido em Mondo scritto e mondo non scritto (CALVINO, 2002a, p. 67-83). Tullio Pericoli, artista plástico amigo de Calvino, estava inaugurando uma nova mostra, Rubare a Klee (1980). É nessa ocasião que se dá a conversa entre os dois artistas, e a parte que nos interessa mais, ligada à tradução. Pericolirecorda a Calvino o exercício de Queneau em Exercices de style (1947), no qual o autor francês narra a mesma história de 99 pontos de vista diferentes. E lembra Calvino de sua tradução de Les fleurs bleues, incitando-o a falar da relação que se estabelece entre tradutor e texto. Calvino responde: "Tradurre è il sistema più assoluto di lettura. Bisogna leggere il testo nelle implicazioni di ogni parola" $\left(\right.$ CALVINO, 2002 ${ }^{\circ}$, p. 74) ${ }^{18}$ e acrescenta que ali se preocupou em restituir os jogos de palavras existentes no texto original, substituindo-os por outros, mas de maneira a manter o ritmo do texto, sua leveza e a mesma necessidade interior. Para Calvino, há um "furto con scasso in ogni lettura, in ogni vera lettura"19 - e a leitura é necessária à tradução - , como quem arromba um cofre para roubar-lhe o segredo. A experiência de ser traduzido é, para ele, do mesmo gênero, um modo de ler a si próprio. "Ogni volta che discuto con un traduttore dei miei libri, nelle lingue che conosco, sono obbligato a ripercorrere il mio lavoro con un altro occhio" (CALVINO, 2002a, p. 75) ${ }^{20}$. Mas o roubo, nesses casos, é previsto e necessário: "Naturalmente i quadri e le opere letterarie sono costruire apposta per essere derubate, in questo senso. Così come il labirinto è costruito apposta perché ci si perda, ma anche perché ci si ritrovi" (CALVINO, 2002a, p. 75) 21. O último aspecto que é preciso comentar, diz respeito aos personagens de Calvino, mais especificamente a um personagem do tradutor, ao personagem tra- 
dutor, ou seja, a Ermes Marana, apresentado em complementariedade ou oposição a Silas Flanery, o personagem-escritor de $\mathrm{Se}$ una notte d'inverno un viaggiatore. Afinal, Ermes é o responsável pelos enganos, pela confusão entre os diversos livros, é falsário por amor, e para ele a literatura só tem valor em virtude de seu poder mistificador. Além de ser um romance, esta obra calviniana é uma exemplificação plena da ficção pós-moderna, ou ao menos assim pode ser lido. E é um livro que retrata, em viés irônico, todo o universo editorial de que Calvino participou em primeira pessoa. É evidente o aspecto de alter ego que o escritor Silas Flanery tem para Calvino. É curiosa essa figura paródica, esse tradutor-personagem que é criador de uma rede de enganos e também é responsável por misturar textos diferentes, que faz passar como se fossem partes do mesmo livro. Esse tradutor falsário, esse trambiqueiro, está ligado à APO, a "Organização do poder apócrifo", que produz livros contrafeitos mundo afora, e é presidente de uma associação ambígua, a OEPHLW ou "Organização para a produção eletrônica de obras literárias homogeneizadas”. Ora, nessa que é uma perfeita paródia do mundo editorial, o tradutor em questão não transmite uma imagem edificante, e está longe de ser aquele tradutor ideal descrito por Calvino nos textos anteriormente comentados. Se é verdade que não raro temos um Calvino que, tanto nos textos ficcionais quanto nos textos ensaísticos, é perfeitamente coerente, a ponto de muitas vezes podermos encetar um diálogo entre os dois tipos de texto, que parecem dialogar numa sinfonia subjacente, ainda resta dar uma resposta ao caráter caricatural desse falsificador que se passa por tradutor... 


\section{Notas}

1. "no francês popular do alunato parisiense", Cf. CALVINO, 2002b, p. 228, tradução minha.

2. MIRANDA, W. M. Italo Calvino, um clássico experimental. In: IV SIMPÓSIO ITALO CALVINO. UFMG, 2014.

3. "Vivi quase ininterruptamente em Sanremo os vinte e cinco anos iniciais de minha vida, numa época em que a população autóctone ainda era a maioria. Vivia num ambiente agrícola, no qual se falava predominantemente em dialeto, e meu pai (...) falava um dialeto muito mais rico e preciso e expressivo do que aquele dos meus coetâneos. Portanto cresci ensopado de dialeto, mas sem nunca aprender a falá-lo (...), (Devo dizer que nunca aprendi a falar fluentemente em nenhum idioma, até porque por índole sempre fui de poucas palavras; e logo minhas necessidades expressivas e comunicativas polarizaram-se na língua escrita)”, tradução minha.

4. Risposte a 9 domande sul romanzo (1959). Hoje em CALVINO, 2002a, p. 34. "Uma vez que determinei que sob meu italiano há o dialeto $\mathrm{x}$, escolherei, de preferência, vocábulos, construções e usos que remetem ao clima linguístico $\mathrm{x}$, em lugar de vocábulos e construções e usos que remetem a outras tradições”, tradução minha.

5. Idem, ibidem. "Só resta mandá-lo para o diabo", tradução minha.

6. Calvino, I. Il midollo del leone. Hoje em Una pietra sopra. Milano: Mondadori, 1995. Ed. Bras: O miolo do leão. CALVINO, 2009, p. 17. "A língua literária deve, isso sim, manter-se o tempo todo atenta aos vulgares falados, e alimentar-se deles e renovar-se com eles, mas não deve se anular neles, nem imitá-los por brincadeira".

7. A trilha dos ninhos de aranha.

8. Dall'opaco [Do opaco] foi primeiramente publicado na revista "Adelphiana”,1971, e a seguir foi publicado em livro na coletânea (póstuma) La strada di San Giovanni (O caminho de San Giovanni). 
9. Idem, ibidem.

10. “O senhor Palomar pensa que toda tradução requer uma outra tradução, e assim por diante. Pergunta-se a si mesmo: "Que quereria dizer morte, vida, continuidade, passagem para os antigos toltecas? E que poderá querer dizer para esses garotos? E para mim?”. Contudo, sabe que não poderia jamais sufocar em si a necessidade de traduzir, de passar de uma linguagem a outra, de uma figura concreta a palavras abstratas, de símbolos abstratos a experiências concretas, de tecer e tornar a tecer uma rede de analogias. Não interpretar é impossível, como é impossível abster-se de pensar”.

11. "Talvez a primeira operação para renovar uma relação entre linguagem e mundo seja a mais simples: fixar a atenção em um objeto qualquer, o mais banal e familiar, e descrevê-lo minuciosamente como se fosse a coisa mais nova e interessante do universo".

12. Na verdade sabe-se de algumas experiências anteriores de tradução por parte de Italo Calvino. Em português, pode-se ver a síntese apresentada por GUERINI E MOYSÉS, 2010/1, p. 29-50.

13. Hoje em CALVINO, 2002A, p. 47-59.

14. “A passagem de um texto literário (...) em outra língua requer, a cada vez, algum tipo de milagre".

15. "Traduzir é o verdadeiro modo de ler um texto" e "para o escritor a reflexão sobre a tradução de um texto seu, a discussão com o tradutor, é o verdadeiro modo de ler a si mesmo, de compreender direito o que ele escreveu, e por que".

16. "O escritor italiano sempre vive em um estado de neurose linguística".

17. “O escritor italiano pode ensinar uma só coisa: enfrentar a depressão, mal de nossa época, defendendo-se com a ironia”.

18. "Traduzir é o método mais absoluto de leitura. É preciso ler o texto nas implicações de toda palavra”. 
19. "Roubo com arrombamento em toda leitura, em toda verdadeira leitura".

20. "Toda vez que discuto com um tradutor sobre os meus livros, nas línguas que conheço, sou obrigado a repercorrer o meu trabalho com outra visão".

21. "Naturalmente os quadros e as obras literárias são propositadamente construídos para serem saqueadas, nesse sentido. Assim como o labirinto é construído propositalmente para que nos percamos nele, mas também para que nos encontremos".

\section{Referências}

ASOR ROSA, Alberto. Natura e Struttura. In Alberto Asor Rosa. Stile Calvino. Torino: Einaudi, 2001, p. 135-159.BERTONE, Giorgio. Italo Calvino Il castello della scrittura. Torino: Einaudi, 1994.

CALVINO, Italo. Il barone rampante. Torino: Einaudi, 1957. Ed. Brasileira: $O$ barão nas árvores. Tradução de Nilson Moulin. São Paulo: Companhia das Letras, 1991.

CALVINO, Italo. Palomar. Torino, Einaudi, 1983. Ed. Brasileira: Palomar. Tradução de Ivo Barroso, São Paulo: Companhia das Letras, 1994. Nota del traduttore. In R. Queneau, I Fiori blu. (1967 primeira edição da tradução italiana; se entende o original francês, a data é 1965) Nella traduzione di Italo Calvino, seconda edizione. Torino: Einaudi, 1984, p. 265-66.

. Eremita a Parigi. Pagine autobiografiche. Presentazione dell'autore. Milano: Mondadori, 1994. Ed. Brasileira: Eremita em Paris. Páginas autobiográficas. Tradução de Roberta Barni. São Paulo: Companhia das Letras, 2006.

. Se una notte d'inverno un viaggiatore. Presentazione dell'autore. Milano: Mondadori, 1994. Ed. Bras. Se um viajante numa noite de inverno. Tradução de Nilson Moulin. São Paulo: Companhia das Letras, 1996. 
. Dall'opaco. In La Strada di San Giovanni. Milano: Mondadori, 1995, p. 95-110 (A primeira publicação deste conto foi In Adelphiana. Milano: Adelphi, 1971) . Ed. Bras. p. 104-118.

. La Strada di San Giovanni. Milano: Mondadori, 1995. Ed Bras. O caminho de San Giovanni. Tradução de Roberta Barni. São Paulo, Companhia das Letras, 2000.

. Il midollo del leone. In: Italo Calvino, Una pietra sopra. Milano: Mondadori, 1980. Ed. Bras: Assunto encerrado. Tradução de Roberta Barni. São Paulo: Companhia das Letras, 2009.

. Mondo scritto e mondo non scritto. A cura di Mario Barenghi. Milano: Mondadori, 2002a.

. Sono nato in America... Interviste 1951-1985. A cura di Luca Baranelli. Introduzione de Mario Barenghi. Milano: Mondadori, 2002b.

GUERINI, Andréia; MOYSÉS, Tânia M. Calvino e a tradução. Cadernos de Tradução, Florianópolis, v.1, n. 25, p. 29-50, 2010.

MOUNIN, G. Teoria e storia della traduzione. Torino: Einaudi, 1965.

Recebido em: 10/06/2015

Aceito em: 07/08/2015 